\title{
Direct measurement of capillary blood flow in the diabetic neuropathic foot
}

\author{
M.D.Flynn ${ }^{1}$, M.E.Edmonds ${ }^{1}$, J.E.Tooke ${ }^{2}$ and P.J. Watkins ${ }^{1}$ \\ ${ }^{1}$ Diabetic Department, King's College Hospital, Denmark Hill, Camberwell, and \\ ${ }^{2}$ Department of Physiology, Charing Cross and Westminster Medical School, London, UK
}

\begin{abstract}
Summary. The two major components of the microcirculation in the diabetic neuropathic foot have been examined in detail. Nutritive capillary blood flow was measured directly using the non-invasive technique of television microscopy, applied to the toe nailfold. Arteriovenous shunt flow was assessed using the technique of laser Doppler flowmetry, applied to the toe pulp. Fourteen diabetic patients with peripheral and autonomic neuropathy, 11 with no clinical evidence of neuropathy and 14 normal subjects were studied. Laser Doppler flowmetry (predominantly arteriovenous shunt flow) was increased more than three-fold $(p<0.01)$ in the diabetic patients with neuropathy compared to control subjects, (median 3.57, interquartile range $2.00-5.32$ volts vs median 0.93 , interquartile range $0.47-2.36$ volts respectively). There was no evidence of skin capillary closure. The calcu-
\end{abstract}

lated capillary blood flow (erythrocyte flux) was significantly increased in the diabetic neuropathic patients compared to control subjects (median 76.4, interquartile range $34.4-109.8$ picolitres/s vs median 23.2 , range $8.0-44.8$ picolitres $/ \mathrm{s}, p<0.01$ ). This study demonstrates that foot skin capillary blood flow is increased in diabetic patients with neuropathy. There is, therefore, no evidence to support the supposition that capillary ischaemia, either secondary to a "capillary steal phenomenon" or "advanced microangiopathy", is a feature of diabetic neuropathy under resting conditions.

Key words: Blood flow, capillaries, diabetic neuropathy, foot, television microscopy.
During the nineteenth century the feet of patients with diabetic neuropathy were observed to be hot and erythematous [1]. More recently an increase in total peripheral blood flow has been demonstrated in the diabetic neuropathic foot [2-5]. This increase in total blood flow is thought to be related to peripheral sympathetic denervation, which results in an increased flow through the arteriovenous shunts [6-9]. In the normal foot arteriovenous shunts have a primary function of thermoregulation [10], and it has been estimated that $80-90 \%$ of total skin blood flow passes through the anastomotic circulation and bypasses the more distal capillary bed [11]. The capillary circulation is situated in parallel to the arteriovenous shunts and has a primary function of skin nutrition. Therefore, skin health ultimately depends on the integrity of the skin capillary vascular bed.

One of the major complications of diabetic neuropathy is foot ulceration. The presence of the autonomic component of neuropathy is a pre-requisite for the development of ulceration in animal studies [12] and abnormal clinical tests of autonomic function are usually found in patients with neuropathic foot ulceration [13, 14]. One consequence of peripheral autonomic denervation is an increase in arteriovenous shunt flow [6]. In order to explain the co-existence of an increased peripheral skin blood flow with neuropathic ulceration, it has been postulated that reduced capillary flow produces skin ischaemia. The capillaries are thought to be either occluded $[15,16]$ or a 'capillary steal' phenomenon is induced by massively increased arteriovenous shunting [17].

Direct measurements of the capillary component of skin blood flow have not been made in the diabetic foot. The only technique that can be used to measure capillary blood flow in an undisturbed vascular bed is the technique of television microscopy. The aim of this study was to use this technique to make direct measurements of capillary flow in the feet of diabetic patients, with and without neuropathy and to compare this with arteriovenous shunt flow assessed by laser Doppler flowmetry. 


\section{Subjects and methods}

Thirty-nine subjects were studied. All were clinically free from peripheral vascular disease having both palpable foot pulses and an ankle systolic/brachial systolic blood pressure ratio of greater than 1.00 [18]. They were divided into three groups, matched for age, and in the diabetic groups, for duration of diabetes. The first group, the diabetic patients with neuropathy, comprised fourteen diabetic patients (11 male) with evidence of both peripheral and autonomic neuropathy. Full clinical details are presented in Table 1. Their mean age was 47.6 (range 23-65) years, duration of diabetes was 18.9 (range 2-44) years.

The second group consisted of eleven diabetic patients ( 8 male) with no evidence of clinical neuropathy, normal autonomic function and normal sensory thresholds. Their mean age was 45.2 (range 23 66 ) years and mean duration of diabetes was 19.5 (range 2-47) years.

The third group, the control subjects, consisted of fourteen nondiabetic normal volunteers (11 male), with a mean age of 44.1 (range 27-67) years.

All patients gave informed consent and the protocol was approved by the hospital ethical committee.

\section{Study conditions}

All subjects were studied in an environmentally controlled room maintained at $22 \pm 0.5^{\circ} \mathrm{C}$ throughout the measurement period. All were allowed to acclimatise lightly clothed, lying supine on a couch. The acclimatisation continued for a minimum of $20 \mathrm{~min}$, until the toe nailfold temperature had reached a stable value.

\section{Assessment of neuropathy}

Autonomic neuropathy was assessed by measuring the mean heart rate variation (HRV) with deep breathing over six breaths using an instantaneous heart rate meter [19]. The heart rate response to a valsalva manoeuvre, the heart rate response to standing and the blood pressure response to standing were also recorded using standard methods [20]. Peripheral neuropathy was assessed by examining the ankle reflex and measuring vibration and thermal sensory thresholds. The vibration sensory threshold was measured using the biosthesiometer (Biomedical Instruments, Newbury, Ohio, USA). The threshold was taken as a mean of five recordings measured on the tip of the right great toe [21]. Thermal sensation was measured on the lateral border of the right foot using a Marstock stimulator (Somedic, Stockholm, Sweden) [21]. The thermal sensory threshold was the mean of the differences between the warm and cold threshold obtained from five measurements.

\section{Blood flow measurement}

Two main investigations were carried out:

1. Measurement of capillary blood flow in the right great toe nailfold, using the technique of television capillary microscopy.

2. The measurement of superficial skin blood flow (predominantly arteriovenous shunt flow) in the pulp of the great toe using the technique of laser Doppler flowmetry.

\section{Recording capillary blood flow}

The right great toe nailfold was illuminated using light from a high pressure mercury vapour lamp (Wotan HBO 50), brought to the skin by a thick fibre optic cable. The nailfold was coated with a thin layer of clear nail varnish to improve the optical properties of the skin. The column of erythrocytes within the capillary was visualised using a X20 objective (Leitz L0.36) and a high resolution television camera
Table 1. Clinical details of subjects

\begin{tabular}{|c|c|c|c|}
\hline Clinical details & $\begin{array}{l}\text { Diabetic } \\
\text { patients with } \\
\text { neuropathy } \\
(n=14)\end{array}$ & $\begin{array}{l}\text { Diabetic control } \\
\text { patients without } \\
\text { neuropathy } \\
(n=11)\end{array}$ & $\begin{array}{l}\text { Nomal } \\
\text { control } \\
\text { subjects } \\
(n=14)\end{array}$ \\
\hline Mean age (years) & $47.6 \pm 2.9$ & $45.2 \pm 4.5$ & $44.1 \pm 3.6$ \\
\hline $\operatorname{Sex}(M: F)$ & $11: 3$ & $8: 3$ & $11: 3$ \\
\hline $\begin{array}{l}\text { Mean duration of } \\
\text { diabetes (years) }\end{array}$ & $18.9 \pm 3.0$ & $19.5 \pm 4.4$ & \\
\hline Insulin treatment & $11 / 14$ & $11 / 11$ & \\
\hline Blood glucose $(\mathrm{mmol} / \mathrm{l})$ & $10.3 \pm 1.0$ & $8.9 \pm 1.2$ & \\
\hline $\begin{array}{l}\text { Haemoglobin } \mathrm{A}_{1} \\
\text { (normal }<8.0 \% \text { ) }\end{array}$ & $11.6 \pm 0.4$ & $10.0 \pm 0.4$ & \\
\hline $\begin{array}{l}\text { Lying systolic blood } \\
\text { pressure }(\mathrm{mm} / \mathrm{Hg})\end{array}$ & $132 \pm 5$ & $131 \pm 4$ & \\
\hline Lying diastolic blood & $75 \pm 3$ & $75 \pm 3$ & \\
\hline Previous foot ulcer & 6 & 0 & \\
\hline $\begin{array}{l}\text { Ankle/brachial systolic } \\
\text { blood pressure ratio } \\
\text { (normal }>1.0 \text { ) }\end{array}$ & $1.25 \pm 0.04$ & $1.13 \pm 0.04$ & \\
\hline $\begin{array}{l}\text { Retinopathy (back- } \\
\text { ground: proliferative) }\end{array}$ & $6: 5$ & $0: 0$ & \\
\hline $\begin{array}{l}\text { Proteinuria (persistent } \\
\text { albustick + ve) with } \\
\text { normal creatinine }\end{array}$ & 3 & 0 & \\
\hline
\end{tabular}

Results expressed as mean \pm SEM

Table 2. Details of tests of autonomic function and peripheral nerve sensory thresholds in the diabetic patients

\begin{tabular}{|c|c|c|}
\hline Investigation & $\begin{array}{l}\text { Diabetic patients } \\
\text { with neuropathy } \\
(n=14)\end{array}$ & $\begin{array}{l}\text { Diabetic control } \\
\text { patients without } \\
\text { neuropathy }(n=11)\end{array}$ \\
\hline $\begin{array}{l}\text { Heart rate variation } \\
\text { with deep breathing } \\
\text { (normal }>10 \text { beats } / \text { min) }\end{array}$ & $5.1 \pm 0.6$ & $19.9 \pm 2.2$ \\
\hline $\begin{array}{l}\text { Valsalva ratio } \\
(\text { normal }>1.20)\end{array}$ & $1.14 \pm 0.01$ & $1.66 \pm 0.06$ \\
\hline $\begin{array}{l}\text { Increase in heart } \\
\text { rate on standing } \\
\text { (normal }>15 \text { beats) }\end{array}$ & $11.4 \pm 2.4$ & $25.0 \pm 4.2$ \\
\hline $\begin{array}{l}\text { Postural change in } \\
\text { blood pressure }(\mathrm{mm} / \mathrm{Hg})\end{array}$ & $-11.3 \pm 3.8$ & $+5.1 \pm 1.4$ \\
\hline $\begin{array}{l}\text { Vibration sensory } \\
\text { threshold on tip of } \\
\text { big toe (normal }<11 \text { volts) }\end{array}$ & $29.9 \pm 4.2$ & $7.5 \pm 0.7$ \\
\hline $\begin{array}{l}\text { Thermal sensory } \\
\text { threshold on lateral } \\
\text { border of foot } \\
\text { (normal }<11 \text { degrees) }\end{array}$ & $23.5 \pm 2.1$ & $7.0 \pm 0.5$ \\
\hline
\end{tabular}

Results expressed as mean \pm SEM

(Hitatchi HV $720 \mathrm{~K}$ ). The image was recorded onto video tape for future analysis using a VHS format videorecorder (Panasonic AG 6200). A recording of one minute's flow was made from each of 12-15 capillaries, recorded sequentially and selected by moving the microscope laterally along the terminal row of nailfold capillaries. 
Toe nailfold temperature was measured using a thermocouple taped to the skin $1 \mathrm{~mm}$ behind the nailfold.

\section{Measuring capillary blood flow}

Capillary blood velocity. One minute's flow was analysed in each of three of the previously recorded capillaries. Only capillaries that remained in clear focus for the full minute were selected for analysis. A strict sampling protocol was adopted for all measurements. Capillary blood velocity (CBV) was measured at five second intervals using a predetermined protocol, by the frame to frame technique [22]. The mean CBV was determined for the three selected capillaries. The coefficient of variation of this analysis is $7.6 \%$, repeated twice in 15 subjects.

Erythrocyte column width. The diameter of the erythrocyte column was measured using vernier callipers. A measurement was made at each time point that a velocity measurement was taken and the mean erythrocyte column width determined.

Flow time. Capillary blood velocity undergoes cyclical variation in velocity and in some capillaries flow may stop and restart periodically. The duration of this stop flow was timed in all recorded capillaries.

Erythrocyte 'flux'. The erythrocyte flux is a measure of capillary volume flow. It is calculated from the measured values of $C B V$ and erythrocyte column width, corrected for the duration of stop flow. The coefficient of variation of 15 duplicate pair analyses is $10.6 \%$.

\section{Laser Doppler flow}

The technique of laser Doppler flowmetry (Periflow PFID, Perimed, Stockholm, Sweden) was used to measure microvascular blood flow in superficial skin vessels [23]. This is a non-invasive technique and gives a voltage signal directly proportional to blood flow in a volume of tissue beneath the probe. This was applied to the pulp of the great toe which is in an area rich in arteriovenous shunts [24], which lie at a depth of $1.0-1.5 \mathrm{~mm}$ below the skin surface [25]. The laser Doppler probe retains sensitivity to this depth [23], and previous studies have suggested that this technique measures arteriovenous shunt flow [26, 27] as well as superficial capillary flow. The capillary component of superficial skin blood flow is quantitatively much less than arteriovenous shunt flow in the pulp of the great toe [11], and thus in the pulp of the great toe the laser Doppler flow signal predominantly represents arteriovenous shunt flow.

\section{Statistical analysis}

The results obtained for measurements of skin blood flow were not normally distributed. Non-parametric methods of statistical analysis have been used. The results are presented as the median (interquartile range) and the Wilcoxon rank sum test and Kendall's method of rank correlation were used in the statistical analysis.

\section{Results}

\section{Skin temperature}

After acclimatisation the diabetic patients with neuropathy and the diabetic control patients were found to have similar median toe skin temperatures: $32.6^{\circ} \mathrm{C}$ (30.4-34.0) in the patients with neuropathy and $31.5^{\circ} \mathrm{C}$ (25.4-32.1) in the diabetic patients without neuropathy. The median skin temperature in the patients with neuropathy was $5.5^{\circ} \mathrm{C}$ higher $(p<0.01)$ than in the normal control subjects at $27.1^{\circ} \mathrm{C}(22.6-30.0)$.

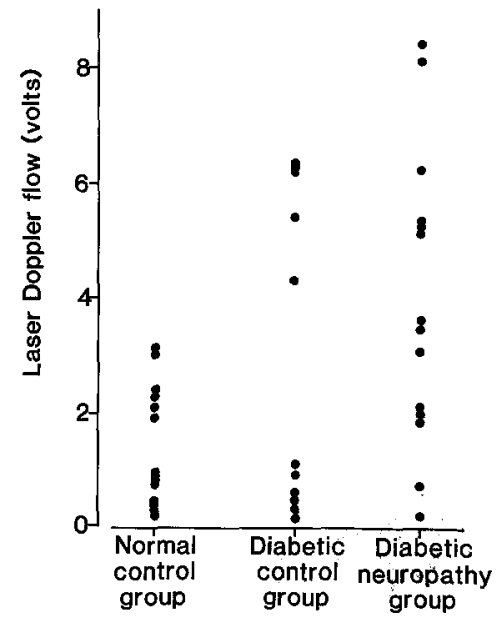

Fig. 1. Laser Doppler flow (predominantly arteriovenous shunt flow) measured at rest in the pulp of the great toe in diabetic patients with neuropathy, diabetic patients without neuropathy and normal control subjects. Diabetic neuropathy group versus normal control group, $p<0.01$

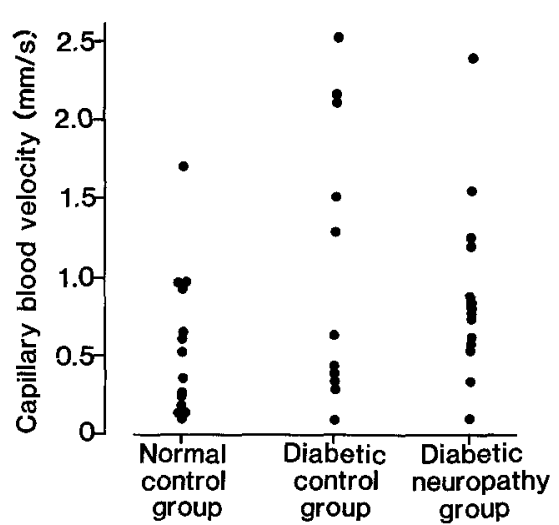

Fig. 2. Capillary blood velocity at rest, measured by frame-frame analysis in diabetic patients with neuropathy, diabetic patients without neuropathy and normal control subjects

\section{Laser Doppler flowmetry}

Laser Doppler flow (predominantly arteriovenous shunt flow) is shown in Figure 1. The median laser Doppler flow was increased more than three-fold $(p<0.01)$ in the diabetic patients with neuropathy compared to normal control subjects: $3.57(2.00-5.32)$ volts in the diabetic neuropathy group and 0.93 $(0.47-2.36)$ in the normal control group. The median value in the diabetic patients free of neuropathy was 1.13 , which was not significantly different from control subjects although the range of values was much greater $(0.45-6.21)$ volts with the suggestion of a bimodal distribution.

\section{Capillary blood flow}

Blood was observed to flow in all capillaries studied during the period of observation. Similar numbers of nailfold terminal row capillaries were observed in each of the three groups $(10.7 /$ linear $\mathrm{mm}$ in diabetic patients with neuropathy, 9.7/linear $\mathrm{mm}$ in diabetic con- 


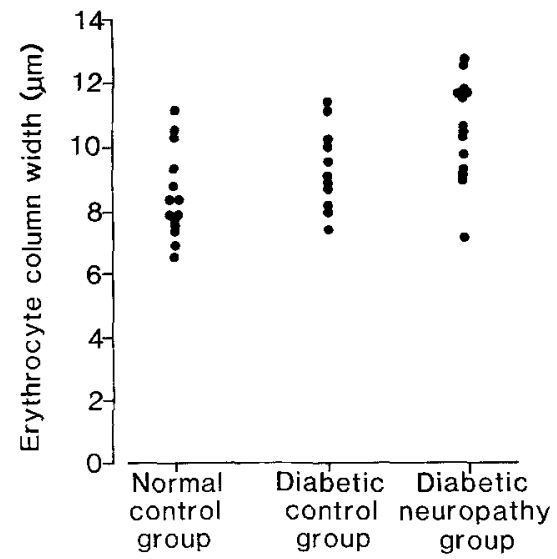

Fig. 3. The diameter of the capillary erythrocyte column in diabetic patients with neuropathy, diabetic patients without neuropathy and normal control subjects. Diabetic neuropathy group vs normal control group, $p<0.01$. Diabetic neuropathy group vs diabetic group without neuropathy, $p<0.05$

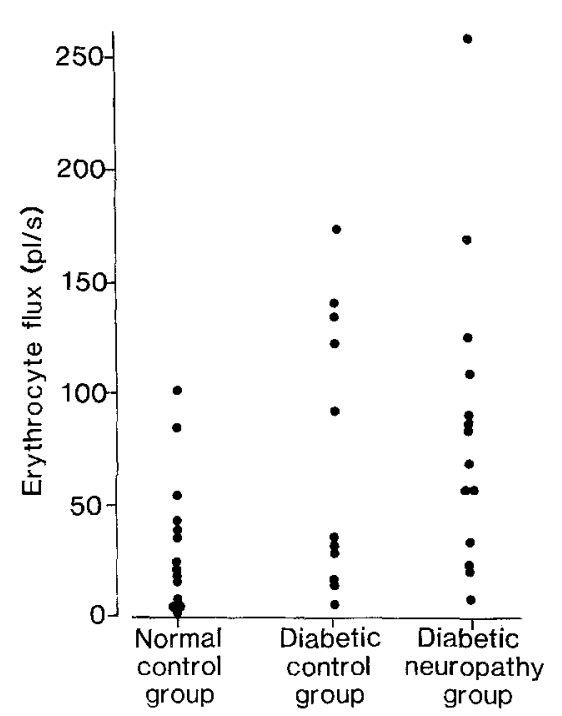

Fig.4. Calculated capillary volume flow (erythrocyte flux) in diabetic patients with neuropathy, diabetic patients without neuropathy and normal control subjects. Diabetic neuropathy group versus normal control group, $p<0.01$

trol patients and 10.4/linear $\mathrm{mm}$ in normal control subjects).

Capillary blood velocity is shown in Figure 2, and was similar in all three groups. The median diameter of the erythrocyte column (Fig.3) in the diabetic patients with neuropathy was $10.6(9.3-11.7) \mu \mathrm{m}$. This was significantly greater than in both normal control subjects, $8.1(7.6-9.3) \mu \mathrm{m}(p<0.01)$ and diabetic control patients, $9.0(8.1-10.2) \mu \mathrm{m}(p<0.05)$. The calculated capillary volume flow (erythrocyte flux) is shown in Figure 4. In diabetic patients with neuropathy the median flow was more than three-fold greater $(p<0.01)$ than in normal subjects: $76.4(34.4-109.8)$ $\mathrm{pl} / \mathrm{s}$ in the diabetic neuropathy group and 23.2 $(8.0-44.8) \mathrm{pl} / \mathrm{s}$ in the normal subjects. In the diabetic patients without neuropathy the distribution of erythrocyte flux appeared bimodal, and did not differ sig- nificantly from either of the other groups at 35.3 $(15.3-134.2) \mathrm{pl} / \mathrm{s}$. The erythrocyte flux demonstrated a significantly positive relationship $(p<0.05)$ with laser Doppler flow in all three groups (diabetic patients with neuropathy $r=+0.41$, diabetic control patients $r=+0.56$ and normal control subjects $r=+0.47$ ).

\section{Discussion}

We have studied, for the first time, the two major components of skin blood flow in the diabetic foot. We have examined the nutritive capillary component of the circulation by television microscopy and assessed the arteriovenous shunt circulation using laser Doppler flowmetry. Our observations indicate that there is a substantial increase in both foot skin capillary blood flow and arteriovenous shunt flow.

Arteriovenous shunt flow, as assessed by laser Doppler flowmetry is markedly increased in diabetic neuropathy. In normal individuals this flow extends over a wide range consistent with its role in thermoregulation. However, in the diabetic patients with neuropathy an even greater range ( 800 -fold) is observed. Some individual diabetic patients who are clinically free from neuropathy also have increased laser Doppler flow. Similar observations have previously been made using plethysmographic techniques to measure total big toe blood flow which includes both skin capillary flow and the much greater arteriovenous shunt flow [4]. One possible explanation of this observation is that peripheral sympathetic denervation may occur before clinically detectable neuropathy $[9,28]$. Flow through arteriovenous shunts is regulated by efferent sympathetic nerve fibres $[10,29]$ and in animal studies arteriovenous shunt flow has been demonstrated to increase considerably after sympathectomy [6]. Release of sympathetic vasoconstrictor tone results in an increase in arteriovenous shunt diameter and an increase from $10 \mu \mathrm{m}$ to $60 \mu \mathrm{m}$ is accompanied by 1000 -fold increase in shunt flow [30]. This is similar to the range of flow measured in this study. Our findings lend strong support to the suggestion that loss of peripheral sympathetic function is a feature of diabetic neuropathy. The present observations of extremely high flow values in some diabetic patients free of neuropathy suggest that loss of peripheral sympathetic function may occur in the absence of clinically detectable abnormalities of both peripheral and central autonomic nerve function.

The capillaries observed under direct vision are both patent and present in normal numbers. This refutes the proposals that advanced 'microangiopathy' or rheological factors leads to capillary closure in the neuropathic foot $[15,16]$. We cannot, however, exclude the possibility that tissue breakdown and ulceration are finally precipitated by acute capillary closure.

In this study we have observed an increase in the 
diameter of the erythrocyte column in patients with diabetic neuropathy. This suggests that the capillaries are dilated, although it could, in theory, merely reflect a reduction of the marginal layer of plasma sheathing the erythrocytes. Increased capillary diameter is, however, a recognised feature of diabetic microcirculation [16]. Capillary blood flow, calculated as the erythrocyte "flux" is undoubtedly increased in diabetic neuropathy, compared to normal subjects. The increased skin temperature in diabetic neuropathy would increase skin oxygen consumption by $70 \%$ [31] and it is conceivable that the increase in capillary flow may be insufficient to meet the increased oxygen demand. The relationship between erythrocyte flux and laser Doppler flow does not support the concept of a capillary steal syndrome, with the highest capillary flow values being found in subjects with the highest laser Doppler flow signals, and vice-versa.

This study demonstrates that capillaries are patent and dilated in the diabetic neuropathic foot and that the capillary blood flow is increased. This study does not provide evidence for capillary ischaemia distal to the high-flow anastomotic shunts in the diabetic neuropathic foot.

Acknowledgements. MDF was supported by the British Diabetic Association. The development of this equipment was made possible by the support of the Wellcome Trust and the British Heart Foundation.

\section{References}

1. Pryce TD (1893) On diabetic neuritis with a clinical and pathological description of three cases of diabetic pseudo-tabes. Brain 16: 416-424

2. Scarpello JHB, Martin TRP, Ward JD (1980) Ultrasound measurements of pulse wave velocity in the peripheral arteries of diabetic subjects. Clin Sci 58: 53-57

3. Edmonds ME, Roberts VC, Watkins PJ (1982) Blood flow in the diabetic neuropathic foot. Diabetologia 22: 9-15

4. Archer AG, Roberts VC, Watkins PJ (1984) Blood flow patterns in painful diabetic neuropathy. Diabetologia 27: 563-567

5. Rayman G, Hassan A, Tooke JE (1986) Blood flow in the skin of the foot related to posture in diabetes mellitus. Br Med J 292: $87-90$

6. Cronenwett JL, Lindenaur SM (1977) Direct measurement of arteriovenous anastomatic blood flow after lumbar sympathetectomy. Surgery $82: 82-89$

7. Partsch H (1977) Neuropathies of the ulcero-mutilating types. Clinical aspects, classification, circulation measurements. Vasa [Suppl] 6: 1-48

8. Boulton AJM, Scarpello JHB, Ward JD (1981) Venous oxygenation in the diabetic neuropathic foot: evidence of arteriovenous shunting. Diabetologia 22: 6-8

9. Watkins PJ, Edmonds ME (1983) Sympathetic nerve failure in diabetes. Diabetologia 25: 73-77

10. Pickering GW, Hess W (1933) Vasodilatation in the hands and feet in response to warming the body. Clin Sci 1:213-223

11. Coffman JD (1972) Total and nutritional blood flow in the finger. Clin Sci 42: 243-250

12. Borkowski M (1973) An experimental study on the role of arte- rio-venous anastomosis in the pathogenesis of trophic ulcer. Arch Immunol Ther Exp (Warsz) 21: 363-375

13. Deanfield JE, Daggett PR, Harrison MJG (1980) The role of autonomic neuropathy in diabetic foot ulceration. J Neurol Sci 47 : 203-210

14. Edmonds ME, Nicoliades KH, Watkins PJ (1986) Autonomic neuropathy and diabetic neuropathic foot ulceration. Diabetic Medicine 3: 56-59

15. Ward JD (1982) The diabetic leg. Diabetologia 22: 141-147

16. Ditzel J (1968) Functional microangiopathy in diabetes mellitus. Diabetes 17: 388-397

17. Ward JD, Boulton AJM, Simms JM, Sandler DA, Knight G (1983) Venous distension in the diabetic neuropathic foot (physical sign of arteriovenous shunting). J R Soc Med 76: 1011-1014

18. Yao ST, Hobbs JT, Irvine WT (1969) Ankle systolic pressure measurement in arterial disease affecting the lower extremity. $\mathrm{Br}$ J Surg 56: 676-679

19. Ewing DJ, Clarke BF (1982) Diagnosis and management of diabetic autonomic neuropathy. Br Med J 285: 916-918

20. Ewing DJ, Clarke BF (1986) Autonomic neuropathy: it's diagnosis and prognosis. In: Watkins PJ (ed) Clinics in endocrinology and metabolism, Vol 15, No 4. Saunders, London Philadelphia Toronto, pp 855-888

21. Guy RJC, Clark CA, Malcolm PN, Watkins PJ (1985) Evaluation of thermal and vibration sensation in diabetic neuropathy. Diabetologia 28: 131-137

22. Bollinger $A$, Butti $P$, Barras J-P, Trachsler $H$, Siegenthaler $W$ (1974) Red blood cell velocity in nailfold capillaries of man measured by a television microscope technique. Microvasc Res 7: $61-72$

23. Nilsson GE, Tenland T, Oberg PA (1980) Evaluation of a laser Doppler flow meter for measurement of tissue blood flow. IEEE Trans Biomed Eng 27: 597-604

24. Grant RT, Bland EF (1931) Observations on arteriovenous anastomoses in human skin and in the birds foot with special reference to the reaction to cold. Heart 15: 385-411

25. Mescon H, Hurley HJ, Moretti G (1956) The anatomy and histochemistry of the arteriovenous anastornoses in human digital skin. J Invest Dermatol 27: 133-144

26. Tooke JE, Ostergren J, Fagrell B (1983) Synchronous assessment of human skin microcirculation by laser Doppler flowmetry and dynamic capillaroscopy. Int J Microcirc Clin Exp 2: 277-284

27. Low PA, Neumann C, Dyck PJ, Fealey RD, Tuck RR (1983) Evaluation of skin vasomotor reflexes by using laser Doppler velocimetry. Mayo Clin Proc 58: 583-592

28. Fagius J (1982) Microneurographic findings on diabetic polyneuropathy with special reference to sympathetic nerve activity. Diabetologia 23: 415-420

29. Delius W, Hagbarth KE, Hongell A, Wallin BC (1972) Manoeuvres affecting sympathetic outflow in human skin nerves. Acta Physiol Scand 84: 177-186

30. Nelms JD (1963) Functional anatomy of skin related to temperature regulation. Fed Proc 22: 933-936

31. Corcoran CA, Yudkin JS (1987) Loss of spontaneous variability of finger tip blood flow in diabetic autonomic neuropathy. Clin Sci $72: 557-562$

Received: 22 February 1988

and in revised form: 1 July 1988

Dr. M.D. Flynn

Medical Unit

Torridge Ward

Level 8

Royal Devon and Exeter Hospital

Barrack Road

Exeter EX2 5DW

UK 